
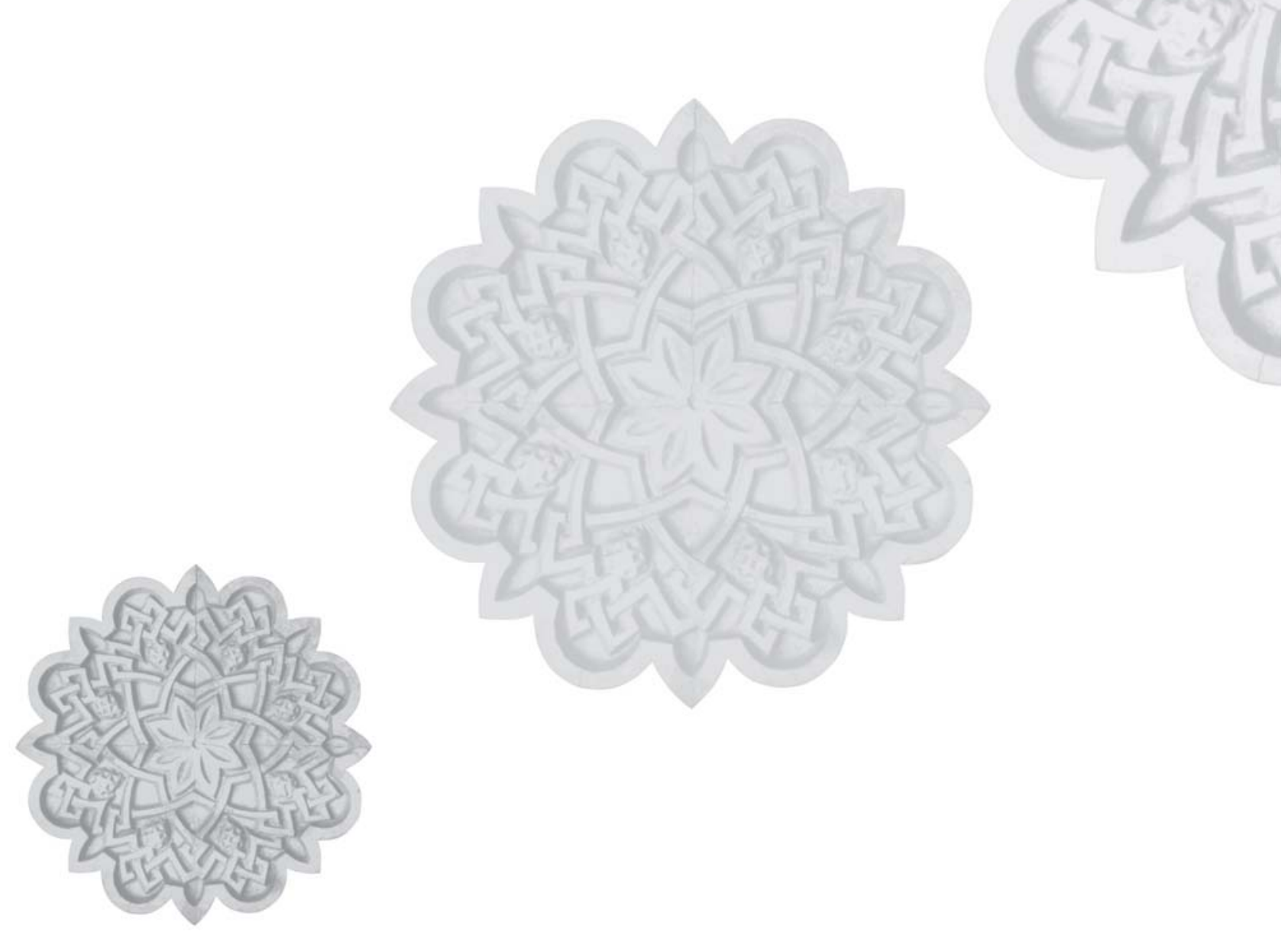


\title{
Etiología parasitaria y obstáculos epistemológicos: el caso de la malaria en Colombia*
}

\section{Parasite ethiology and epistemological obstacles: the case of malaria in Colombia}

\author{
Victoria Estrada Orrego \\ Bióloga e historiadora, integrante del \\ Grupo de Historia de la Salud \\ Crra 64, 51-19 \\ Apartamento 401 Bloque 84 \\ Medellín, Colombia \\ vestrada@epm.net.co
}

Jorge Márquez Valderrama

Escuela de Estudios Filosóficos y Culturales de la Universidad Nacional de Colombia

Calle 59A n ${ }^{\circ}$ 63-020 Bloque 46 Autopista Sur

Medellín, Colombia

jmarquez@unalmed.edu.co

ORREGO, Victoria E.; VALDERRAMA, Jorge M. Etiología parasitaria y obstáculos epistemológicos: el caso de la malaria en Colombia.

História, Ciências, Saúde - Manouinhos,

Rio de Janeiro, v.14, n.1, p.91-118, ene.-mar. 2007.

Muestra el proceso que condujo a la medicina colombiana al descubrimiento y aceptación de las causas del paludismo, una enfermedad que aún azota en el país a grandes zonas cálidas y húmedas. Para el cumplimiento de este proceso una nueva generación de médicos tuvo que abandonar la antigua teoría de los miasmas y apropiarse de la teoría de los vectores, pero en este proceso la medicina pasteuriana fue más un obstáculo que una condición de posibilidad para la emergencia de un nuevo programa de investigación. Incluso aparecieron descubridores autóctonos de nuevos parásitos que fueron desmentidos por los hallazgos en medicina tropical. Gracias a todos ellos hoy el paludismo no pertenece a los fantasmas que merodean en el sentido común.

PALABRAS CLAVE: historia de la parasitología, microbios, pasteurianismo, vectores, medicina tropical.

ORREGO, Victoria E.; VALDERRAMA, Jorge M. Parasite ethiology and epistemological obstacles: the case of malaria in Colombia.

História, Ciências, Saúde - Manquinhos, Rio de Janeiro, v.14, n.1, p.91-118, Jan.-Mar. 2007.

In this article we show the process that led Colombian medicine toward the discovery and acceptance of the causes of paludism, a disease that still haunts the large hot and humid zones in the country. To carry out this process, a new generation of physicians had to overrule the old miasma theory and accept the vectors theory. In this regard, however, Pasteurian theory was also more of an obstacle than a condition for the emergence of a new research program. As a matter of fact, native discoverers of new parasites were disclaimed by the findings in tropical medicine. Thanks to all of them, nowadays paludism does not belong to the phantoms that pillage in the usual direction.

KEYWORDS: history of parasitology, microbes, Pasteurianism, vectors, tropical medicine. 
* Este trabajo se inscribe en la línea de investigación Historia de las Prácticas de la Salud y es uno de los resultados de la investigación "De gusanos, microbios y parásitos: comienzos de la parasitología en Colombia" que presentó Victoria Estrada Orrego como monografía para graduarse como historiadora en la Universidad Nacional de Colombia, dirigida por Jorge Márquez Valderrama (Medellín, julio de 2004).
$\mathrm{E}$ ste artículo es uno de los resultados de una investigación histórica sobre la emergencia de la parasitología y la medicina tropical en Colombia. Estudia una controversia entre teorías científicas rivales. Nuestra vía de interrogación no es la historia social de la medicina, sino más bien la historia de la medicina a secas. De acuerdo a nuestra hipótesis, la descripción del habitus y de las condiciones socioeconómicas y culturales de los actores implicados en un problema de controversia científica no bastan para explicarlo. Aunque esa descripción ayuda a comprender parte de las posiciones de sujeto adoptadas por los protagonistas de la controversia, no se puede reducir la explicación de la pugna entre teorías científicas a ese contexto.

Como ha mostrado la historiadora Sandra Caponi (2003), investigaciones históricas recientes consideran que la malaria ${ }^{1}$ emergió en el campo biomédico a finales del siglo XIX como el modelo heurístico de la medicina tropical. El estudio del paludismo permitió formular preguntas que condujeron a esclarecer la etiología de enfermedades como la fiebre amarilla, la enfermedad del sueño, la leishmaniasis y la enfermedad de Chagas.

En la documentación médica colombiana no se encuentran huellas de las hipótesis de la medicina tropical antes del comienzo del siglo XX. Esto es explicable porque los acontecimientos fundadores de ese nuevo campo de investigaciones datan de la última década del siglo XIX. La escuela londinense de medicina tropical (The London School of Tropical Medicine) fue fundada por Patrick Manson, en 1898, y su obra Tropical Diseases fue publicada ese mismo año. Ambas empresas ganaron prestigio rápidamente en la medicina internacional. La hipótesis de Alphonse Laveran, enunciada en 1892, sobre el papel de mosquitos en la transmisión de patologías infecciosas, tuvo como adeptos a muchos investigadores asignados a misiones científicas de países colonialistas y casi ninguno entre los pasterianos del Instituto Pasteur de París (Caponi, 2003).

En esa misma época, Colombia tenía una situación política distinta a la de muchos territorios africanos y asiáticos colonizados por potencias europeas, pues no era colonia y en su territorio no se desarrolló una 'medicina colonial'. Sin embargo, el país reunía condiciones sociales, económicas y biogeográficas favorables a la propagación de enfermedades transmitidas por vectores.

A finales del siglo XIX, la medicina colombiana estaba dominada, por una parte, por un conjunto de discursos médicos cuyos autores trataban de explicar fenómenos epidémicos reunidos por ellos bajo la categoría vaga de 'las fiebres' (Márquez Valderrama, 2004); y, por otra parte, otros discursos médicos que dejan ver la acogida temprana de la 'medicina moderna' (Márquez Valderrama, 2005), es decir la nueva etiología microbiana. A ese conjunto se añaden, a comienzos del siglo XX, los textos de médicos que aceptan 
la etiología basada en la hipótesis del papel de vectores en la transmisión de enfermedades.

Nuestro interés en este artículo es él análisis histórico de las relaciones entre la emergencia de la parasitología y el conocimiento del paludismo en Colombia. Para ello recurrimos a un corpus de investigaciones realizadas a comienzos del siglo $\mathrm{XX}$, orientadas a esclarecer la etiología, las formas de transmisión y la profilaxis de la malaria. Estos estudios no pueden comprenderse sin analizar la mezcla de hipótesis y teorías, así como la competencia entre doctrinas y prácticas médicas, en el momento en que surge la medicina tropical en el mundo occidental (Márquez Valderrama, 2005).

Esta mezcla no se desplegó sin controversias y, atendiendo al objeto particular de este artículo, nos centraremos en la acaecida a propósito del paludismo.

La documentación deja ver la presencia y la influencia en las principales escuelas médicas de Colombia (la de Bogotá y la de Medellín) ${ }^{2}$, de los dos programas de investigación etiológica más importantes en ese momento en el mundo, el mansoniano y el pasteriano.

\section{Topografía médica y etiología del paludismo}

En los discursos de la transición entre la doctrina de los miasmasfundamento de la higiene y la patología infeccionistas - y la medicina tropical, pervivió un imaginario del medio geográfico que conjugaba el miedo a peligros considerados endémicos del trópico, con posiciones "aclimatacionistas" respecto a la salud y la enfermedad. Estos planteamientos, incluso en Colombia, se inscribían en un campo discursivo decimonónico compartido por geógrafos, médicos y naturalistas, cuyo objeto era difuso y diversamente nombrado: "higiene y patología de los países cálidos", "climatología médica”, "geografía médica" o "topografía médica" ${ }^{3}$ Este campo heterogéneo de discursos convergía en la pregunta por la posible correlación entre los factores meteorológicos y la aparición de ciertas patologías en determinadas regiones. ${ }^{4}$

El tránsito de las tesis infeccionistas hacia la medicina pasteuriana y la apropiación local de los primeros descubrimientos de la medicina tropical puede verse por primera vez en la tesis de medicina de David Pérez (1901). No hubo trasformaciones radicales, las novedades se aunaron al discurso que había y sólo con el tiempo se depuraron y prescindieron de los modelos anteriores. La asociación neohipocrática entre clima, temperamento y enfermedad se lee todavía en la tesis del doctor Pérez, que tiene como objetivo hacer "un compendio de la higiene especial de las regiones cálidas de Colombia" (Pérez, 1901, p.13).

El sintagma 'regiones cálidas', la preocupación por los tráficos, la división en climas "sanos" y "malsanos" y el interés por describir a los habitantes y sus costumbres, muestran el nexo del texto de Pérez 
con el aclimatacionismo ${ }^{5}$ y la teoría de los miasmas. Sin embargo, en otro capítulo aparecen refinadas mezclas de esta doctrina con nociones de la medicina pasteuriana, aunque filtrada por la obra del parasitólogo Alphonse Laveran. Así, escribía Pérez (1901, p.36):

la patología de las regiones cálidas es muy compleja por estar sometida á la influencia de dos grandes elementos patógenos: el calor y las bacterias nocivas. Estos dos elementos se combinan y refuerzan de tal manera que el primero viene á agregarse á la influencia nociva del segundo para favorecer su multiplicación y aumentar su virulencia.

El autor describe el hematozoario de Laveran ${ }^{6}$ y explica que el paludismo no se produce por generación espontánea, sino por un agente microscópico favorecido por el calor. Los pantanos no desprenden miasmas sino gérmenes, la condición necesaria para que se transmita la enfermedad no es el pantano sino el "germen palúdico". Pérez acepta como agente causal del paludismo al hematozoario de Laveran y reconoce el papel de los mosquitos en su transmisión. Propone una profilaxis general basada en la historia natural de los vectores y la entomología:

Sólo ciertas especies de mosquitos son susceptibles de propagar el paludismo; de este modo se explica que en determinadas localidades en que aquellos abundan sean salubres.

El microbio del paludismo se desarrolla sufriendo transformaciones bastante complicadas en el cuerpo de aquellos insectos que han chupado sangre palúdica; al cabo de 8 ó 10 días los gérmenes abundan en la secreción salivar de los tales, y cuando los infestados pican á individuos sanos, les inoculan esos gérmenes: de ahí resultan, en la profilaxis del paludismo, dos indicaciones nuevas: de una parte esforzarse en destruirlos; de otra, protegerse de las picaduras. (Pérez, 1901, p.49-50)

Como medidas profilácticas Pérez propone el saneamiento de localidades palúdicas y la profilaxis individual. ${ }^{7}$ En ambas mezcla el neohipocratismo con la naciente medicina tropical:

Para precaverse de la acción de los climas cálidos y preservarse del impaludismo que en ellos reina, deben desaguarse los terrenos palustres, edificar en lugares elevados y secos, lejos de pantanos y ciénagas y hacer edificios altos y abrigados.

Los moradores de estas tierras se encerrarán antes de que el sol se oculte, y no saldrán al trabajo sino cuando este astro este ya en el horizonte.

Los alimentos deben ser abundantes, nutritivos y de fácil digestión, el agua hervida y filtrada, y las bebidas alcohólicas usadas con mucha parsimonia. 
Se evitarán los trabajos largos y penosos, y los excesos de todo género, especialmente los venéreos.

Los vestidos deben abrigar bien y cubrir toda la periferia del cuerpo; se mantendrá esmerado aseo en ellos, lo mismo que en la persona y en la habitación.

Los pesares, las molestias, las preocupaciones, así como los golpes y las heridas, despiertan el impaludismo latente en alguna de sus variadas formas.

Los mosquitos y los bichos de todo género deben ahuyentarse con fumigaciones o destruirse por medio de hogueras; pues ellos son los inoculadores del bacilo de Laveran que da origen á ese proteo de manifestaciones palúdicas ..., el único medio infalible para evitar la malaria es no acercarse á los lugares palustres. (Pérez, 1901, p.66-67).

Aunque Pérez reconoce cierta acción a los mosquitos como inoculadores, aún no admite plenamente una etiología basada en los vectores, pues afirma que los mosquitos y los bichos inoculan el bacilo de Laveran, asimila el hematozoario a una bacteria y exhibe las resistencias de muchos pasteurianos frente a este organismo difícil de comparar con las bacterias por ser un parásito que sufre alternancia de generaciones. Habrá que esperar aún algunos años para que los postulados de la biogeografía y de la medicina tropical respecto al clima como factor secundario muestren que enfermedades parasitarias como la malaria aparecen por la distribución de especies en determinadas zonas de vida y no por el clima en general.

\section{Un descubridor: parásitos de la sangre y de la naturaleza}

A comienzos del siglo XX, un destacado investigador colombiano de la etiología del paludismo fue el doctor Juan Bautista Montoya y Flórez, médico, cirujano, bacteriólogo y profesor de la Facultad de Medicina de Medellín entre 1894 y $1937 .{ }^{8}$

En 1904, Montoya presentó ante la Academia de Medicina de Medellín una memoria en la que, a pesar de reconocer el descubrimiento por Alphonse Laveran del plasmodium causante del paludismo, pretendió mostrar su hallazgo de un nuevo agente:

En nuestros palúdicos no se encuentra el hematozoario descrito por el Sr. Dr. Laveran en las fiebres intermitentes de la zona templada o pretropical; aquí lo que pulula en número prodigioso en la sangre de los palúdicos es un micro-organismo dotado de gran movilidad y de una forma discoide.

En ningún caso ha faltado, de manera que puedo afirmar del modo más formal que este nuevo parásito es constante en el paludismo de esta región tropical. 
Este mismo germen, ó al menos una variedad de él, es muy frecuente en los batracios, saurios, aves y en algunos mamíferos domésticos de las localidades palustres. (Montoya y Flórez, 1904a, p.3)

Para aislar el "parásito del paludismo", Montoya siguió el procedimiento divulgado por Émile Roux y los pasteurianos: aislar, cultivar e inocular el germen. Según Montoya, el nuevo parásito palúdico es perfectamente cultivable y por eso se diferencia de los parásitos de Laveran. ${ }^{9}$ Inoculó cultivos del parásito de los palúdicos por vías intravenosa y gástrica en cuatro pollos, una gallina, una liebre y dos curíes, después observó, midió diariamente la temperatura y examinó la presencia de parásitos en la sangre de estos animales. Además, inoculó experimentalmente a una persona. Era un paciente del Hospital San Juan de Dios de Medellín, “Luis M. Gómez, sujeto de unos 40 años de edad". Desde hacía varios años, Gómez padecía "una micosis fungóides en tumores"; los de la cabeza, "profundamente ulcerados", lo retenían en el Hospital bajo los cuidados del doctor Montoya. Éste le había inyectado "dos centímetros cúbicos, de un cultivo líquido de 22 días" del "parásito del paludismo". Según Montoya (1904a, p.19), "... dicho individuo no ha tenido nunca paludismo, ni actualmente le da fiebre, ni sudores a ninguna hora". Antes de la inoculación, la sangre no presentaba parásito alguno y la temperatura era normal. El objetivo de esas inoculaciones no era terapéutico, sólo se trataba de verificar en un humano la posibilidad de infectar con un cultivo del "parásito" y obtener artificialmente el paludismo. El médico hizo un seguimiento diario del paciente, intentó la infección vía oral y concluyó que eran posibles dos vías de infección experimental: la "inyección intramuscular" y "la ingestión de cultivo" (p.20-21). Montoya asumió estos "hechos" como confirmación de su hipótesis según la cual, en el hombre, el "parásito" del paludismo se transmitía más fácilmente por ingestión:

La experiencia hecha en Gómez, y en los animales está a favor del origen del paludismo por ingestión, ya de frutas ácidas ...; de leche con un principio de fermentación; bebidas fermentadas, como el guarapo y la chicha, huevos crudos de gallinas palúdicas, y carnes medio crudas de animales palúdicos; ó ya de aguas impuras en ciertas épocas del año que coinciden con la floración de ciertas plantas, tales como las Erythrinas. (Montoya y Flórez, 1904a, p.22)

En cuanto a la relación entre "verano" e "invierno" y "las recrudescencias de fiebres palúdicas", el médico negó la intervención de los mosquitos preconizada por Laveran:

... la verdadera causa de esas epidemias o recrudescencias es, probablemente, la siguiente: en verano las charcas, estanques y 
en general las aguas de poco declive y corriente se convierten en depósitos ó pudrideros de varias maceraciones vegetales que contienen en estado saprofítico infinidad de microbios, entre otros el parásito del paludismo; ahora bien, los primeros aguaceros torrenciales barren todas estas maceraciones ó cultivos microbianos y los echan en el cauce de los arroyos y ríos de agua potable, envenenando transitoriamente, si puede decirse así, las fuentes de que se surten los hombres y los animales domésticos. (Montoya y Flórez, 1904a, p.23)

De acuerdo con la teoría de Montoya, los parásitos permanecen idénticos pese a que se transmitan por la sangre del cordón umbilical de la madre palúdica al hijo y aunque vivan en animales de las zonas palustres ${ }^{10} \mathrm{o}$ en "estado saprofítico" en la naturaleza.

\section{La "caquexia palúdica" o tuntún}

La tesis de Montoya puede resumirse así: el parásito del paludismo está en todo lugar húmedo o que contenga humedad. En su afán por defender su idea de la ubicuidad del microbio en las regiones palustres, no diferenciaba los cuadros clínicos de la malaria y la anquilostomosis. Pensaba que esta última patología - delimitada por los médicos de las zonas cafeteras ${ }^{11}$ - era sólo una especie del género "paludismo", es decir, el "paludismo no febril", "caquexia palúdica" o tuntún, manifiesta como anemia profunda, palidez, gran fatiga y "palpitaciones en la cabeza" y causada por la contaminación del agua por la cereza del café.

En una discusión con el doctor Miguel María Calle ${ }^{12}$, durante una sesión ordinaria de la Academia de Medicina de Medellín (Acta, 1904a), Montoya identificó nuevamente el tuntún con el paludismo y el doctor Calle contestó sus proposiciones. Si las fiebres palustresdijo Calle - pertenecen a las regiones cálidas y si el doctor Montoya ha dicho en su informe "Visita científica a la zona del Ferrocarril" que todas las anemias de esa zona cálida y baja son palúdicas, aunque en muchos individuos no se observen "manifestaciones ruidosas del paludismo", se le puede preguntar "qué opina él de las anemias graves ... que se desarrollan en nuestros climas templados, tan frecuentes especialmente en los peones destinados al beneficio del café" (Acta, 1904a, p.60).

Según explicó Calle, los casos de la zona cafetera pertenecían a una población de "clima reconocidamente sano", en donde hay un gran número de "tuntunientos", ninguno de los cuales presenta "la hipertrofia del bazo y del hígado", pero sí "una gran dilatación estomacal". Calle buscaba aclarar ante la Academia de Medicina que no se debía confundir, como lo hacía Montoya, tuntún [anquilostomiasis] y paludismo, y sus argumentos provenían de la observación 
clínica, herramienta de diagnóstico, eficaz aun antes del auge de la microbiología.

Al contestar los argumentos precisos del doctor Calle, Montoya complicó aún más su sistema explicativo (Acta, 1904a, p.60-61). Para él, el paludismo no es un estado patológico del cuerpo o una enfermedad, sino un conjunto de cualidades patógenas inherentes al clima y a la constitución de los individuos, esto ratifica su concepción arcaica de las fiebres. Al final del artículo "Parásito del paludismo en Colombia", el médico subrayaba la acción terapéutica pero no preventiva de la quinina ${ }^{13} \mathrm{y}$ "otros antisépticos" ${ }^{14}$ en el paludismo y concluía:

... la cuestión queda sobre el tapete para que los nuevos observadores juzguen y decidan si el nuevo parásito palúdico es una planta ó animal; ... experiencias más perfectas ... que las mías sentarán de un modo definitivo, sí verdaderamente se trata de un germen patógeno ó simplemente de un comensal sanguícola muy frecuente en estos climas y sólo importante desde el punto de vista de la biología general. (Montoya y Flórez, 1904a, p.31)

El concepto de "parásito" que elabora Montoya no tiene que ver con las concepciones mansonianas. Esto se hace evidente cuando se propone comprobar si se trata de "un germen patógeno" o "de un comensal sanguícola". La expresión "comensal sanguícola" y la idea de su pertinencia exclusiva para la "zoología", aluden a la relación parasitaria conocida por la biología del siglo XIX, en la cual el parásito es un animal que vive y depende de la sustancia de otros (Littré, Robin, 1898).${ }^{15}$ Debemos subrayar además la adhesión de Montoya a la doctrina pasteuriana de los gérmenes, su teoría para explicar el origen y la propagación del "parásito del paludismo" se basa en la teoría del contagium vivum, pero mezclada con ciertas ideas de la parasitología del siglo XIX anteriores al pasteurianismo ${ }^{16} \mathrm{y}$ al programa de investigación de la medicina tropical. ${ }^{17}$

En otro artículo, Montoya (1904b) contesta al parasitólogo Alphonse Laveran al afirmar que los cuerpos de morfología variable causantes del paludismo descritos por éste son, en muchos casos, "una faz de la reproducción de los elementos figurados de la sangre humana y de muchos animales" - entre ellos caballos - y no la causa eficiente de ese mal. El error se debía, según Montoya, a dificultades de observación y al desconocimiento de la trasformación de las células sanguíneas.

En agosto de 1904, al informar sobre su "visita científica" a la zona de la construcción del Ferrocarril de Antioquia, Montoya aseguró que el agua era el principal vehículo del germen palúdico y se opuso a la teoría de los huéspedes intermediarios: 
Ya Hipócrates (nacido 470 años antes de J.C.) admitía que las aguas estancadas ó cenagosas producían el crecimiento del bazo y fiebres intermitentes rebeldes; desgraciadamente teóricos modernos han tratado de desviar el criterio y hacer creer que el paludismo es inoculado exclusivamente, ó poco menos, por ciertos mosquitos zancudos, de alas manchadas, llamados Anopheles. Este es un error, y mis investigaciones bacteriológicas sobre el paludismo y las aguas de las localidades palustres del río Magdalena, han demostrado que Hipócrates tenía razón y que el microbio del paludismo existe indiscutiblemente en ciertas aguas de los terrenos gredosos. (Montoya y Flórez, 1904c, p.68)

El médico también advirtió que el trasnocho y los excesos amatorios predisponían al paludismo o le hacían retornar las fiebres a los palúdicos crónicos. Como medidas profilácticas propuso desecar la laguna próxima a la zona de trabajo, vigilar que el nivel de las aguas fuera constante y remplazar las malezas por árboles que secan los terrenos, es decir eucaliptos (Montoya y Flórez, 1904c, p.70).

En ese informe Montoya buscaba validar sus aseveraciones, ya no basado en Pasteur y en la microbiología médica, sino en Hipócrates y en la medicina neohipocrática, y para ello desatiende las diferencias teóricas y epistemológicas entre las dos corrientes y las sitúa en un mismo nivel explicativo. Montoya utiliza a Hipócrates como autoridad para sustentar su teoría y rechaza los estudios sobre la acción de los anofeles en la transmisión del paludismo, calificándolos de error. ${ }^{18}$ El médico conocía los estudios sobre el mosquito - divulgados por la prensa científica del mundo aunque cita muy poco a Manson, a Ross y a otros que defendían la hipótesis de los huéspedes intermediarios. La única alusión a Manson que hace Montoya en su informe la usa para defender las cualidades profilácticas del zumo de limón frente al paludismo:

Sir Patrick Manson hablando del limón como profiláctico del paludismo dice: "Crudeli speaks highly of lemon decoction (made by boiling for half an hour á sliced lemon in á pint and á half of water straining, diluting and sweetening) as á prophylactic: its use can do no harm, and it is á pleasant, slightly tonic, and slightly aperient beverage, well suited as drink in hot climates. The decoction made from one lemon may be taken daily in divided doses". (Montoya y Flórez, 1904c, p.71) ${ }^{19}$

Sobre esta cita y sobre la forma de citar de Montoya debemos observar que: (1) La cita está en inglés, algo inusual en la literatura médica colombiana de esa época. (2) Manson no se refiere al zumo de limón, quien lo hace es un tal Crudeli citado por él. (3) Además de atribuirle a Manson afirmaciones ajenas, Montoya no menciona las medidas profilácticas propuestas por The London School of Tropical Medicine. En síntesis, Montoya se apropia del 
prestigio de una autoridad con cuyas tesis no quiere comprometerse, lo cual demuestra que sus argumentos no obedecen al desconocimiento de los trabajos de Manson y su escuela, sino a una oposición categórica a ellos.

Cuando Montoya incluye entre las medidas profilácticas la desecación de la zona, no sigue a la medicina tropical que propone medidas similares para acabar con las larvas de los mosquitos, se acoge a la medicina neohipocrática que busca evitar la putrefacción de materias vegetales; también lo propone como medio de supresión de las aguas estancadas propicias a la generación del "germen palúdico".

En la teoría de Montoya sobre el paludismo, por definición, el medio y las personas de las regiones cálidas son palustre ${ }^{20}$ “"zonas palustres", "localidades palustres", "animales palustres" - y el microbio está en todas partes: agua, frutas, animales, bebidas y personas. Esto le impide a Montoya comprender una teoría exclusivista de la transmisión del paludismo, donde los mosquitos anofeles son los únicos "inoculadores". Es evidente que la mezcla de doctrinas (neohipocrática y pasteriana) constituye el obstáculo epistemológico ${ }^{21}$ para que Montoya acepte nuevas teorías etiológicas. La bacteriología y la etiología infeccionista se combinan en la obra teórico-práctica de Montoya para conformar un programa de investigación que él habría de continuar en su labor docente.

\section{Los émulos de Laveran}

Francisco Betancourt, alumno de Montoya, sustentó en Medellín la tesis "Contribución al estudio del paludismo en Antioquia", cuyos conceptos, teorías y argumentos permiten observar cómo el pasteurianismo se erigió temporalmente en obstáculo para parte de la medicina antioqueña de aquel momento. Desde la introducción, Betancourt se vincula a una polémica que, según su maestro, estaba demostrando cierta inexactitud en los descubri-mientos de Laveran, y manifiesta que con su estudio pretende responderle a ese debate sobre la verdadera causa del paludismo:

[por] el interés que han despertado en el mundo científico las investigaciones y descubrimientos recientes de célebres médicos coloniales en Argelia, la India y Cuba, tales como E. Legrain, A. Treille, Jorge Treille, Bruce, Coronado, quienes contradicen y corrigen la teoría y conclusiones de Laveran ... sobre la causa mórbida del paludismo que no es según el sentir de aquellos, el hematozoario de Laveran, sino otro definido según estudios actuales y consistente en un micro-organismo de forma semejante á micrococos. (Betancourt, 1904, p.9) 22 
$\mathrm{Al}$ advertir que era seguidor de Juan B. Montoya, Betancourt traza la dirección de su estudio. Emulando a su maestro, Betancourt desmiente la posibilidad de "inoculación del paludismo por los mosquitos" o por vías de trasmisión distintas al agua, el aire y la inoculación sanguínea inducida en el laboratorio; su primer argumento contra la hipótesis del mosquito inoculador es de puro sentido común:

se ha creído hasta ahora en la inoculación del paludismo por los mosquitos y los zancudos, la variedad de anópheles principalmente, pues entre otras cosas - se ocurre observar que los mosquitos abundan entre nosotros y existen en todos los meses del año y es bien sabido que los meses de recrudescencia para las fiebres palustres corresponden á la época veranosa y días que siguen a las primeras lluvias, siendo lógico deducir de la presencia constante de la causa el resultado continuo de la enfermedad, con solo las diferencias locales ó de otra especie semejante. (Betancourt, 1904, p.12).

Este razonamiento se podría expresar como un silogismo: si hay mosquitos todo el año y transmiten el paludismo, entonces debería haber paludismo todo el año. En esta lógica simplificadora no caben relaciones complejas como las que describían los investigadores de la escuela mansoniana (Caponi, 2003, p.138).

Como agentes de transmisión del paludismo, los anofeles estaban fuera del horizonte enunciativo y del campo explicativo de Betancourt y de Montoya, quienes se empecinaban en los dogmas pasteurianos porque buscaban - como lo hacía su modelo francés, Émile Legrain ${ }^{23}$ - el agente patógeno del paludismo según los procedimientos de la bacteriología ya mencionados. Además, la ausencia en Colombia de estudios detallados en zoología médica ${ }^{24}$ muestra la ausencia entre los médicos de la pregunta por los ciclos de vida de los mosquitos.

Según la historiadora Sandra Caponi (2003, p.128, 138), los estudios de historia natural aplicados a la etiología no afectaron las encuestas bacteriológicas, pero sí la de la medicina tropical. Además, en esta última tenían menos importancia las opiniones y dominaba la observación detallada del comportamiento de posibles vectores y de sus relaciones con los humanos.

Por otra parte, muchos enunciados de Betancourt y de Montoya se acercan más a una medicina neohipocrática que a la bacteriología médica, y por eso a ambos les preocupaba el clima y los meteoros. Sin embargo, éste es más bien un refinamiento de la conjunción causal entre factores físicos, factores biológicos y hábitos. Para Betancourt (1904, p.13), causas mecánicas como el calor, ayudan a la fermentación de "materias" y "productos orgánicos de distinto origen" y forman "medios de cultivo" donde se "multiplica el agente 
patógeno de las fiebres de los países cálidos". Las "emanaciones de las [aguas] estancadas y de los pudrideros" viajan por el aire ("donde flota el parásito") y, a través de ellas, penetra el "parásito del paludismo" en el organismo de trabajadores y viajeros de "constitución debilitada".

Fiel a los trabajos del médico pasteuriano Émile Legrain, Betancourt compara los agentes patógenos de las fiebres palúdicas - y no sólo porque penetran por vía pulmonar - con el bacilo de la tuberculosis y el neumococo. Las etiologías de la gonorrea y la tuberculosis son para él modelos de explicación causal del paludismo. ${ }^{25} \mathrm{El}$ médico utiliza términos tomados del sentido común, donde se conjugan mitos populares sobre causas de los estados febriles y propuestas moralizadoras:

El parásito palúdico puede probablemente ser huésped saprófito en el organismo: así se explica la recaída frecuente de los enfermos en los accesos febriles, después de largo tiempo de cuidados, de tal modo que parece que no aguardaran para revelar su presencia como el neumococo, sino cualquier ruptura de equilibrio en el funcionamiento de los aparatos. Explica también lo mismo el que individuos que en territorios maláricos no han presentado accidente ninguno febril, al salir a una tierra fría, sean atacados de fiebres que parecen salir de su estado latente al influjo de corrientes de aire frío, y el que se determinen por dormir desabrigados los individuos, siguiendo la costumbre de los climas cálidos, lo cual es sumamente nocivo; lo mismo que los excesos amorosos, las borracheras, las fatigas etc. (Betancourt, 1904, p.17).

Betancourt también conocía el Tratado del paludismo de Laveran (1898) y señala que los parásitos "no se han podido cultivar". En este último punto se sitúan los mayores ataques de los médicos pasteurianos al trabajo de Laveran y sus alumnos. ${ }^{26}$ Las ideas de Montoya y Betancourt coinciden con las de Legrain en su oposición a Laveran. Los autores analizados muestran que lasideas pasteurianas se convierten en un obstáculo para la asimilación de las innovaciones explicativas y los procedimientos deinvestigación de la medicina tropical.

\section{Una profilaxis del paludismo}

El pasteuriano Betancourt repite las medidas profilácticas consignadas en el citado informe de Montoya a la Junta Directiva del Ferrocarril de Antioquia (Montoya y Flórez, 1904c). A causa de los miasmas que se desprenden de las ciénagas que abundan en "parásitos palúdicos", hay que evitarlas o destruirlas, tener cuidado especial con las aguas detenidas, sembrar Eucaliptus rostrata para "ayudar al drenaje de los terrenos". En cuanto a la construcción de viviendas, 
hay que buscar lugares elevados, bien aireados, lejos de arroyos, ríos y manantiales, lejos de la "infección malárica". Es necesario purificar el agua de beber mediante un "filtro de piedra, barro ó arena", y en las localidades palustres, "se hervirá el agua antes de filtrarla, para hacerla completamente aséptica", "el zumo de limón mezclado al agua puede también purificarla" (Betancourt, 1904, p.42).

Persisten los enunciados de la antigua higiene, aunque no se puede asegurar que el alumno de un pasteuriano convencido siga al pie de la letra esa "mitología médica"27; la presencia de términos como 'miasmas', 'infección palustre', 'localidades eminentemente palustres', revela al menos la dificultad de estos médicos para comprender la propuesta etiológica de la medicina tropical. La mezcla de doctrinas complica aún más la comprensión histórica del pasteurianismo local. Por un lado, Betancourt propone medidas profilácticas basadas en una medicina neohipocrática y por otro, las "propiedades preventivas" del zumo de limón aparecen respaldadas por una autoridad científica y no por la sabiduría popular como se pudiera creer: "Sir. Patrik Manson concede propiedades preventivas al zumo de limón. El Dr. Montoya y Flórez ha demostrado el poder bactericida del limón en cultivos microbianos de distintas especies: ha visto él la rapidez con la cual una gota del zumo destruye los microorganismos" (Betancourt, 1904, p.44). Esta es la única mención de Betancourt a Manson (simple recurso de autoridad), calcada de Montoya. Las medidas profilácticas que recomienda para los cuarteles o dormitorios de peones muestran cómo evade la medicina tropical:

No se dejará en ningún caso que los peones duerman en el suelo para evitarles la humedad del terreno que los predispone á enfermedades de los riñones, al beri beri y al tuntún ó anemia de los trópicos; las camas estarán separadas por un metro de distancia por lo menos, provistas de mosquiteros (toldillos) en los puntos donde hay mucho mosquito zancudo: aquellos tienen la ventaja de hacer más tranquilo el sueño de los peones preservándolos de las úlceras de las piernas, tan frecuentes en las tierras cálidas y que generalmente son debidas á la inoculación de un microbio especial por los mosquitos .... Los peones no deben remangarse los pantalones, para evitar las llagas producidas por los mosquitos. (Betancourt, 1904, p.42-43)

Ahí se reconoce a los mosquitos como agentes trasmisores de microbios, pero no el del paludismo, sino "un microbio especial" no identificado. Recomendar el uso del mosquitero no parte de la misma convicción que inspira a la medicina tropical, e impedir que los peones duerman en el suelo para evitar la anemia no se inspira en las mismas razones que aduce Manson respecto a la filariosis. 
Aunque cita a Manson, la tesis de Betancourt nada tiene que ver con la medicina tropical. ${ }^{28}$ La mezcla de medicina e higiene pasteurianas con la doctrina infeccionista introduce más mitos de los que desaloja; una noción como la de organismo vector no cabe en esa curiosa mezcla, a Betancourt y a su maestro les parece increíble que un mosquito pueda ser el agente portador de un germen del paludismo.

Una parasitología del siglo XX fundada en el conocimiento de la etiología basada en los vectores - fiebre amarilla, paludismo, mal de Chagas, peste bubónica -, que involucre tanto la entomología médica como las relaciones entre los organismos, y de éstos con los medios interior y exterior, no se haya en los textos médicos analizados. Las dificultades para que tal concepción se instale no son específicas de la medicina colombiana, sino más bien de la medicina pasteuriana.

Un verdadero interés institucional por la medicina tropical sólo apareció en el contexto de otros acontecimientos, a saber: la llegada al país de médicos educados en el mundo anglosajón, la creación de cátedras de 'clínica de las enfermedades tropicales', el encuentro con la Misión Rockefeller y la realización de estudios médicos basados en el modelo parásito-vector. A partir del contacto directo del doctor Roberto Franco ${ }^{29}$ con la escuela londinense, comienza en Colombia la formación de una nueva generación de médicos formados en la medicina tropical. El médico e historiador Emilio Quevedo y sus colaboradores (Quevedo et al., 2004, p.153-161) señalan la importante labor del médico Roberto Franco como "quien introdujo, en la primera década del siglo XX, la parasitología y la medicina tropical" en Colombia.

\section{Objeciones a los pasteurianos}

Gracias a su experiencia en bacteriología, sus investigaciones sobre el carate publicadas en Francia (Montoya y Flórez, 1897), la creación del primer curso de bacteriología en Colombia y su práctica quirúrgica, Juan Bautista Montoya y Flórez era muy reconocido en las tribunas médicas colombianas. Sin embargo, no todos los médicos simpatizaban con sus hipótesis sobre el descubrimiento de un nuevo parásito del paludismo.

Un buen ejemplo es evidente en la carta de Alphonse Laveran dirigida al médico colombiano Luis Zea Uribe, profesor de bacteriología de la Facultad de Medicina de Bogotá. La traducción fue publicada por la Revista Médica de Bogotá en noviembre de 1903. He aquí algunos apartes: 
París, 5 de Septiembre de 1905 [sic].

Mi querido colega: una señora me entregó ... las preparaciones de sangre palustre, que usted ha tenido la amabilidad de dirigirme.... yo participo enteramente de su manera de ver en lo que se refiere al parásito descrito por el Dr. Montoya y Flórez. Yo he examinado como usted algunas de las preparaciones del Sr. Montoya, y no me parece dudoso que nuestro colega ha tomado alteraciones de los glóbulos por hematozoarios.

No se debe dejar acreditar la opinión de que el paludismo de Colombia es debido á un hematozoario diferente del que lo produce en otros países.

\section{A. Laveran}

En la misma revista apareció un extracto de la nota que el profesor Laveran le presentó el 8 de mayo a la Academia de Medicina de París, donde denuncia el error frecuente de "tomar por pseudoparásitos las alteraciones de la sangre normal y confundirlos con hematozoarios endoglobulares" (Laveran, 1903, p.100). El médico le recomienda a los observadores que se familiaricen con el estudio de los hematozoarios y adopten para su investigación "la técnica especial que permite obtener preparaciones de sangre bien fija y bien coloreada, única manera de evitar las causas de error" (Laveran, 1903, p.102). Los médicos de Bogotá, que se oponían a la hipótesis del descubrimiento de un nuevo germen palúdico, se apoyaron en Laveran para objetar las afirmaciones de Montoya.

En diciembre de 1904, a propósito de la Memoria publicada por Montoya (1904a), el doctor Luis Zea Uribe escribió un artículo donde se oponía al 'descubrimiento', esta vez con argumentos más contundentes. El tono irónico revela su postura:

No es poco, por ejemplo, que una entidad mórbida como el paludismo, que desde el año 1880 entro en el campo de la verdadera experimentación entre las manos de los profesores de la talla de Laveran, que hizo el descubrimiento del parásito; de Metchnikoff, que confirmó sus estudios siete años después; de Mac-Callun, Danilewsky, Roberto Koch, Manson, Ross, Grassi, Dionisi, Leichman [sic], Daniels y mil más ..., coincidiendo sus autores en el hecho de la verdad del descubrimiento del médico francés; no es poco, decimos, que una entidad patológica que se presenta con idénticos síntomas en las hoyas ardientes de los ríos africanos Gambin, Senegal, Nilo etc., en las llanuras anegadizas de la India, y la Indochina, en el archipiélago Malayo y en la América del Sur y del centro, etc. etc. sea producida en todas esas partes por un hematozoario que todos pueden estudiar, y aquí entre nosotros, en nuestro turbio Magdalena, es decir, en circunstancias propicias de humedad y de calor, sea producida dicha entidad por otro microorganismo distinto, que ha sido revelado por la habilidad 
técnica y laboriosidad del Dr. Montoya y Flórez. (Zea Uribe, 1904, p.130-131)

No son, pues, comparables los estudios de esos médicos extranjeros con los de Montoya. Además, la "aseveración categórica de que no existe entre nosotros el parásito de Laveran", le parece "bien extraña" a Zea Uribe, porque él también hizo análisis microscópicos de "sangre palúdica" y siempre halló el hematozoario de Laveran en los enfermos que no habían tomado quinina (Zea Uribe, 1904 , p.131).

Zea Uribe (1904, p.132) afirma que "el método aconsejado por el Dr. Montoya y Flórez para preparar la sangre seca y extendida", ... "el mismo que traen algunos tratados franceses", es "defectuoso é inseguro". Luego critica los procedimientos y denuncia la carencia de reactivos con calidad suficiente para realizarlos: "Por ello, para evitar accidentes, y con el objeto de obtener preparaciones de nitidez perfecta". Sugiere adoptar el procedimiento de Leishman ${ }^{30}$, seguido por la Escuela de Medicina Tropical de Londres (p.133) ${ }^{31}$ Este procedimiento se adoptó en el curso de bacteriología de la Facultad de Medicina de Bogotá. Lo que muestra que, por la vía del estudio de Laveran y de los demás trabajos basados en sus hallazgos, los médicos de Bogotá, y no los de Medellín, entraron tempranamente en contacto con la medicina tropical inglesa.

Zea Uribe muestra el enfrentamiento entre los modelos teóricos y los protocolos de las escuelas de medicina francesa e inglesa. Se manifiesta en el ámbito local el debate mundial entre pasteurianos y tropicalistas. En un polo estaban Montoya y Betancourt, de Medellín, ya expuestos arriba. En el otro polo se hallaban Franco, Zea Uribe y sus alumnos, de Bogotá, quienes siguieron a Laveran y a Manson para argumentar que existe un mismo hematozoario de morfología variable en todos los lugares del mundo donde hay paludismo. La batalla entre pasteurianos y tropicalistas fue ganada poco después por Manson y sus discípulos. El triunfo se manifestó con la generalización de una nueva profilaxis del paludismo basada en la medicina tropical.

En 1905, el mismo Émile Legrain afirmó en un texto traducido del francés para los Anales de la Academia de Medicina de Medellín, que "antes de encontrar en el mosquito la clave del problema [la malaria] la medicina oficial proponía el uso de la quinina para reducir la mortalidad y el uso del eucaliptus 'el árbol salvador' que cortando el viento que venía de los pantanos, impedía, decían, que el miasma palustre llegara al colono" (Legrain, 1905, p.139).

Según Legrain, la profilaxis del paludismo toma una nueva orientación y se reduce a dos proposiciones: impedir que el hombre infecte al mosquito e impedir que el mosquito infecte al hombre. Legrain (1905, p.147) asegura que "es necesario reglamentar en las tierras palustres el trabajo en los campos, entrar todas las tardes antes de 
salir el sol y no salir después de que alumbre de nuevo para evitar el mosquito, además de promover la destrucción de larvas y el aislamiento de los pacientes". Se podría creer que las hipótesis de los médicos de Medellín perderían validez después de esta publicación de 1905, pero en dos artículos publicados en otra revista nacional, en ese mismo año, los estudios de Montoya sobre el paludismo encontraron un nuevo reconocimiento. ${ }^{32}$

\section{Los mosquitos como agentes de transmisión}

Lo que hoy es un saber compartido por la comunidad científica internacional sobre algunas enfermedades parasitarias, entre 1898 y 1904 significó un debate que culminó en el establecimiento del papel de los vectores en la propagación y transmisión de enfermedades infecciosas.

Empeñada en la difusión del pasterianismo, local e internacional, la prensa científica colombiana de ese período divulgó escasamente los descubrimientos de Finlay, Manson, Ross y Grassi sobre los vectores de la filariosis, la malaria de las aves y la malaria humana. Esa difusión se hizo mediante reseñas de artículos de investigadores extranjeros que aparecían en la revista a la prensa científica internacional. En los artículos de autores colombianos se citaba a los extranjeros, pero sobre todo para oponérseles. ${ }^{33}$

Esto se debió quizá a la gran ascendencia de los pasterianos en las principales revistas médicas colombianas. Cuando la revista Anales de la Academia de Medicina de Medellín vuelve a aparecer al finalizar la Guerra de los Mil Días (1899-1902), en junio de 1902, y hasta junio de 1904, Montoya y Flórez fue su redactor principal. Al mismo tiempo, entre agosto de 1897 y marzo de 1908 su amigo José María Lombana Barreneche, pasteriano convencido, fue el redactor de la Revista Médica de Bogotá. Esas dos circunstancias le permitieron a Montoya sostener sus posturas científicas con pocos contradictores. Además, contó con la posibilidad de apoyarse en la única revista científico-médica que funcionaba en ese momento en Medellín.

Además, durante sus investigaciones sobre el carate, realizadas en Francia, el doctor Montoya descubrió varias especies del hongo Aspergillius (Montoya y Flórez, 1897; 1898). Este logro lo hizo célebre internacionalmente y quizá su "hallazgo" de una nueva especie de parásito del paludismo en Colombia (1904) estuvo enmarcado por su deseo de darle continuidad al reconocimiento ya obtenido. Lo que nos muestra su habitus profesional (Bourdieu, 2003) es el peso que en sus actuaciones como científico tuvo la escuela en la que se formó. En efecto, quizá era el pasterianismo el paradigma que le permitía mantener y alimentar su prestigio como investigador, por ser el lugar desde donde podía convertirse de nuevo en 
"descubridor" ante la comunidad científica internacional. En la nueva ciencia de los vectores, esa empresa era mucho más difícil.

En Colombia, las primeras huellas de la aceptación de la teoría de los mosquitos como agentes de trasmisión del paludismo, se encuentran en algunas tesis de la Facultad de Medicina de Bogotá posteriores a $1906 .{ }^{34}$ En la tesis de Jorge D. Rueda (1907), dirigida por el doctor Roberto Franco Franco, ya se acepta que el paludismo es "una enfermedad inoculada al hombre por una variedad de mosquito Anophelinae y caracterizada por la presencia en la sangre del enfermo, de parásitos especiales llamados hematozoarios de Laveran". Ya es claro que el agente de trasmisión es el anofeles. Lo que antes se designaba con nociones diversas como "intoxicación telúrica", "malaria" o "fiebre intermitente", se unifica en el concepto de "paludismo".

Rueda describe el rechazo inicial a los trabajos de Laveran y subraya la suspicacia de algunos observadores italianos que, en 1890, sostenían "que los hematozoarios del paludismo pertenecían á distintas especies y que había una relación constante entre tal ó cuál forma, y tal ó cuál manifestación clínica de la fiebre". Según Rueda, esta hipótesis se confirmó "de manera convincente é irrefutable por inoculaciones experimentales" (Rueda, 1907, p.12), pues los médicos ya dominaban la transmisión experimental en humanos:

$1^{\circ}$ La infección se transmite con seguridad cuando se hace en las venas o debajo de la piel, de un individuo sano, la inyección de sangre proveniente de un palúdico. $2^{\circ}$ En un mismo enfermo un tipo febril jamás es otro. $3^{\circ}$ Los tipos parasitario o febril son en el individuo contaminado, siempre idénticos á los del individuo cuya sangre se ha inoculado. $4^{\circ}$ Cuando la transformación se creyó posible, se trataba indudablemente de una invasión secundaria por un parásito distinto al de la primera infección." (Rueda, 1907, p.12).

Ya no había dudas sobre la transmisión natural de la enfermedad: “ 5 No sólo por inoculación directa de sangre palúdica humana se reproduce el tipo febril en el individuo inoculado, sino también cuando un individuo sano es picado por un Anopheles maculipennis, previamente infectado, chupando la sangre de un individuo atacado de un tipo febril conocido." (Rueda, 1907, p.12).

El obstáculo pasteuriano no aparece y el texto de Rueda se basa en la medicina tropical: cita a Manson sin aislarlo del contexto de su programa de investigación. El recurso a la entomología médica es contundente, pues se precisa la especie del anofeles. Rueda define taxonómicamente los hematozoarios del paludismo, explica sus ciclos de vida y describe las tres especies que producen el paludismo: “P. malaria, P. vivax, P. Falciparum" (Rueda, 1907, p.13-16).

El autor describe los elementos de la sangre en estado normal y luego la técnica de diagnóstico y la fijación de las preparaciones, 
destaca la necesidad de intensificar la práctica de laboratorio para adquirir destrezas en la distinción entre parásitos y alteraciones artificiales de la sangre y luego concluye: "Llamamos especialmente la atención hacia esta parte para evitar descubrimientos y descripciones de nuevos parásitos que perjudican al microscopio y á quien los hace." (Rueda, 1907, p.25). De ahí en adelante, los ojos del experimentador deberán guiarse por la teoría para evitar descubrimientos como el de Montoya. ${ }^{35}$

La principal novedad del texto de Rueda es que promulga la necesidad de realizar estudios de entomología médica en Colombia: "Altamente interesante sería hacer entre nosotros una verdadera enquête [sic] para averiguar si algunas de las especies de mosquitos anteriormente descritas existen en Colombia, si hay variedades hasta hoy desconocidas $y$, finalmente, si existe algún otro insecto capaz de inocular el paludismo." (Rueda, 1907, p.29).

A partir de ese momento, en los estudios del paludismo en Colombia, se consideran indispensables investigaciones en entomología e historia natural, como las que propone la medicina tropical. También las medidas profilácticas siguen los lineamientos de esa medicina: proteger al hombre de picaduras de insectos, destruir los anofeles y suprimir pantanos y aguas estancadas. ${ }^{36}$

En el estudio de Rueda no hay rastros de las doctrinas médicas del siglo XIX, ni de los obstáculos epistemológicos que la medicina pasteuriana impuso. Esto se debe quizás a que se inscribe sin vacilación en el nuevo programa de investigación impulsado por su director de la tesis, el doctor Roberto Franco quien formó las primeras generaciones de médicos colombianos en medicina tropical (Quevedo et al., 2004, p.160; ver también nota 29 de este artículo), la cual, aunada a la nueva parasitología, comienza a abrirse campo en la medicina colombiana. La higiene, la profilaxis y la prevención se verán transformadas a partir de ese momento.

\section{La medicina tropical en el terreno}

Emiliano Henao Melguizo (1864-1938) inició estudios en el Seminario de Medellín y luego de trasladarse a Bogotá se graduó como médico en la Universidad Nacional. En 1893, cuando vivía en Puertoberrío (una importante estación del Ferrocarril de Antioquia, por ser el principal puerto antioqueño sobre el río Magdalena), le ofreció sus servicios a la Junta Directiva del Ferrocarril de Antioquia y fue nombrado médico-jefe permanente (Restrepo, 2004, p.52). Henao permaneció en ese cargo hasta 1936 y luego fue consultor del Departamento Sanitario de la misma empresa.

A pesar de los pocos datos de archivos, parece ser que el encuentro, en 1904, entre el prestigioso profesor universitario J.B. Montoya y Flórez y el médico jefe del hospital del Ferrocarril, E. Henao, fue 
breve y sin efectos sobre la práctica médica en el Ferrocarril. Es notorio el silencio del doctor Henao durante y después de la visita de Montoya, burócrata llegado de la capital y redactor de un reporte médico donde contraría las bases científicas de la campaña antimalárica adelantada por Henao. Sin embargo, dos meses después de la publicación de ese reporte ocurre algo extraordinario en el periódico del Ferrocarril. El informe de Juan B. Montoya y Flórez fue publicado el $1^{\circ}$ de noviembre de 1904 en el periódico El Ferrocarril de Antioquia, Medellín (Montoya y Flórez, 1904d) y el $1^{\circ}$ de enero de 1905, en el mismo periódico (n 139), bajo el título "Los mosquitos", se publicaron dos textos que apoyaban la tesis del papel de los mosquitos en la propagación de la fiebre amarilla y del paludismo. ${ }^{37}$

Los puntos de vista de ambos doctores sobre la malaria y la uncinariasis divergían mucho. Sin embargo, esto se puede constatar más por los caminos posteriores de cada uno que por sus trayectorias anteriores al encuentro, debido a las lagunas en la documentación. El encuentro deja entrever dos modos de razonamiento científico sobre un mismo problema. El de E. Henao se basa en las prácticas clínica y terapéutica, sus registros cuantitativos cotidianos de resultados clínicos así lo atestiguan. El modo de Montoya es el uso de las pruebas de laboratorio (ya descritas) para defender su propia teoría. Henao es un clínico de hospital que basa sus pruebas en la medición estadística de sus éxitos terapéuticos. Montoya basa las suyas en ensayos de laboratorio bacteriológico, además ha sabido escalar en los ámbitos académicos. Por su parte, Henao se preocupa más por obtener argumentos en defensa de sus prácticas de medicalización de los peones: higiene, terapéutica, clínica y medicina laboral (Restrepo, 2004; Estrada Orrego, 2004). Además, el uso de la quina como preventivo - y no sólo como paliativo de las fiebres palúdicas -, promovido por Henao en diversas campañas en la zona del Ferrocarril, fue rechazado por Montoya (1904d). Sin embargo, que el uno trabajara en clínica bacteriológica y el otro en clínica terapéutica y preventiva de hospital, no supone de antemano que deberían haber llegado a resultados divergentes. Lo que los distancia en sus prácticas y en sus conclusiones son sobre todo las teorías etiológicas en que cada uno se apoya. Es claro que el problema tiene que ver más con el enfrentamiento entre dos teorías científicas (la etiología pasteriana y la etiología por vectores) y menos con el habitus y las condiciones socioeconómicas y culturales de los actores implicados.

En 1909, el doctor Henao se interesó por "ponerse al corriente de la Higiene moderna, que vale más que la terapéutica, pues impedir las enfermedades es mucho menos costoso en vidas y en dinero que curarlas" (Restrepo, 2004, p.54). En ese mismo año se ausentó de su puesto como director del Hospital del Ferrocarril y se fue a seguir el curso sobre enfermedades tropicales que dictaba The London School 
of Tropical Medicine. A su regreso, en 1910, Henao publicó un artículo donde menciona los descubrimientos de la escuela londinense relacionados con algunas enfermedades - espirilosis, paludismo, filariosis - y sus modos de transmisión. El médico destaca "en el activo de las Escuelas Tropicales, los millones de vidas salvadas, los de enfermedades prevenidas ó vencidas y la cuantiosa riqueza pública economizada que esos factores representan" (Henao, 1910, p.104).

La reseña es detallada, menciona a los profesores y resume el contenido de los cursos "para estimular á nuestros prácticos de los malos climas colombianos á probar un curso en alguna de las sesiones que se hacen en el año", incita a los médicos locales para que asistan a esos cursos:

La escuela de Medicina Tropical de Londres se abrió hace diez años, por iniciativa particular, y hace parte de la Universidad de Londres. Por ella han pasado yá cerca de mil médicos, prácticos de los climas cálidos .... Nuestra Nación es la que menos ha figurado en ella ... ha habido médicos de las Repúblicas centroamericanas, del Brasil, Venezuela o Méjico, en los diez años que lleva de vida ha visto en sus aulas solamente cuatro médicos colombianos (Henao, 1910, p.104-105).

Otro rasgo importante del trabajo de Henao sobre el paludismo fue el uso continuado de la quinina preventiva en el hospital rural que dirigía. Todo esto lo alejaba de las opiniones dominantes en la Facultad de Medicina de Medellín, sin que su prolongada labor en zonas de malaria y uncinariasis endémicas dejara de ubicarlo a la vanguardia de la medicina tropical en Antioquia.

Según Emiliano Henao, instaurar medidas contra el paludismo basadas en la medicina tropical podía traer grandes beneficios económicos a la empresa del Ferrocarril de Antioquia. Con ese argumento presentó una ponencia ante el Segundo Congreso Médico Nacional (Henao, 1916), en la que exponía su 'lucha antimalárica' adelantada como campaña oficial de la empresa desde 1911. Henao adoptó plenamente la profilaxis tropicalista consistente en protección contra las picaduras de los anofeles, destrucción de criaderos de larvas y suministro de habitaciones cómodas y amplias para los obreros. Sus reportes de 1911 y $1912^{38}$ muestran una disminución de los casos de malaria que benefició a la vez el nivel de salud de los trabajadores y las finanzas de la empresa. ${ }^{39}$

Episodios y circunstancias de su vida hicieron que las opiniones de Emiliano Henao sobre el paludismo fueran distintas a las de los médicos de la Facultad de Medicina de Medellín. Las observaciones de Henao son relevantes porque él era médico de empresa y de terreno y no de clientela privada, en su época el paludismo era una enfermedad dominante en grandes concentraciones humanas como 
empresas, guerras y procesos de colonización (Grmek, 1999; Caponi, 2003; Delaporte, 2004; Restrepo, 2004).

Gracias a la actualización científico-médica que Henao promovió en el Ferrocarril de Antioquia, entraron en acción una medicina de la fuerza laboral y una medicina social no basadas en la beneficencia sino en la economía de la salud. Henao promovió por ejemplo los seguros de invalidez y las pensiones por accidente de trabajo, lo que constituyó una de las primeras formas de manifestación del 'derecho a enfermarse' en Colombia. ${ }^{40}$

Los estudios médicos colombianos posteriores a 1913 buscaron extender las medidas profilácticas para romper la cadena parásitomosquito-hombre, aunque en muchas zonas las medidas no llegaron a aplicarse. Ya no hubo más vacilación en los discursos médicos en cuanto a la etiología basada en los vectores, el paludismo se convirtió en modelo de investigación y la medicina tropical conquistó su propio espacio.

\section{NOTAS}

${ }^{1}$ La etimología del término malaria proviene del italiano mala aire (mal aire, miasma), el médico colombiano Jorge Rueda lo describió en 1907 como un término usado desde tiempo atrás por los médicos y el vulgo de Italia, para designar la enfermedad supuestamente causada por el aire pestilencial de los pantanos (Rueda, 1907, p.7).

2 Por escuelas médicas se entiende aquí no solamente las instituciones universitarias de formación de médicos (Facultad de Medicina de la Universidad Nacional de Colombia en Bogotá, creada en 1867 y Facultad de Medicina de la Universidad de Antioquia, creada en Medellín en 1871), sino también los otros lugares también institucionales - de debate teórico, a saber las sociedades científicas (Academia Nacional de Medicina para Bogotá y Academia de Medicina de Medellín), (Obregón Torres, 1992) y las Juntas de Higiene estatales (nacionales, departamentales y municipales). En esos tres lugares se puede la intervención casi de los mismos actores médicos como expertos y miembros del cuerpo médico de cada ciudad.

3 De ese campo discursivo mencionamos, entre otros, los estudios de Posada Arango (1887), Uribe Ángel (1888), Botero Guerra (1889) y Andrade (1891).

4 A fines del siglo XIX se le sumará a este conjunto la pregunta por la influencia de factores biológicos patógenos, suscitada por los descubrimientos de Louis Pasteur.

${ }^{5}$ La medicina higienista francesa del siglo XIX se inscribe en la tradición naturalista del aclimatacionismo, que es distinta de la tradición biogeográfica que inspiró a Charles Darwin y Patrick Manson: "aclimatar un individuo, raza o especie, después de haberla transportado a otro país, es decir, fuera de su armonía natural, es habituarlos a la nueva condición de existencia y generar que conquisten la armonía con el nuevo medio". (Caponi, 2003, p.141)

6 "los hematozoarios del paludismo se presentan bajo cuatro formas: 1ำ Cuerpo esférico (representan la forma

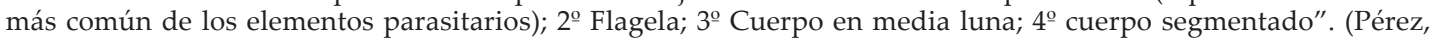
1901, p.42)

7 También propone usar la quinina en la profilaxis y como medida terapéutica: “Una quinina de buena calidad no debe faltar al viajero ni al habitante de las regiones cálidas. Puede decirse de quien la tiene que en el bolsillo lleva la tranquilidad, la salud y hasta la vida. La quinina, el mercurio y el opio forman la trípode sobre la cual descansa el arte de curar". (Pérez, 1901, p.67)

8 Para comprender diversas posiciones de sujeto de este investigador es necesario que precisemos algunos rasgos de su biografía intelectual. A pesar de ser el hijo mayor de una numerosa y humilde familia de colonos antioqueños, gracias a la holgada situación financiera de su abuelo materno, le fue posible hacer estudios de medicina en Bogotá (1886-1891) y en París (1892-1894). En 1892-1893 hizo el curso Microbio Técnico del doctor Émile Roux en el Instituto Pasteur de París. En ese mismo año, asistió a los cursos del doctor Charcot en la Salpetrière, hizo experimentos con hipnosis y fue nombrado, en 1896, miembro de la Sociedad Hipno- 
sicológica de París. Los documentos de archivo muestran parte de su ejercicio profesional, en el cual es manifiesta su concepción de la medicina como empresa liberal (anuncios publicitarios de la Revista de Farmacia de Medellín, enero 1896). En el laboratorio bacteriológico que funcionó en su casa del centro de la ciudad impartía enseñanzas de bacteriología práctica a los estudiantes de la Facultad de Medicina de la Universidad de Antioquia, pues en 1896, inauguró en Medellín la enseñanza de la bacteriología, práctica y teórica. En el mismo año también ofreció Montoya, en la prensa comercial, el servicio de hospedaje medicalizado para las personas acomodadas de fuera de la capital en una institución que él creó y llamó Casa de Salud. Su laboratorio fue además la única empresa privada de análisis de muestras que hubo en la ciudad hasta 1915. En París trabajó entre 1896 y 1898 en el laboratorio del dermatólogo Saboureaud, donde pudo continuar sus investigaciones sobre la enfermedad llamada carate, endémica en Colombia en esa época. Descubrió el hongo causante del carate en 1896 y publicó su célebre tesis, laureada, "Recherches sur les caratés de la Colombie", con la que se graduó, a sus 31 años, como doctor en medicina de la Facultad de París (Montoya, 1951, p.42-43). En 1900, hizo cursos de especialización en cirugía en Londres y en 1901 creó en la Universidad de Antioquia la cátedra de clínica quirúrgica de la cual fue profesor hasta su muerte en 1937 (p.47).

9 "Mis primeros cultivos fueron obtenidos sembrando sangre del bazo en una infusión de flores frescas de Erythrina (Písamo) al 10\%, peptonizada y glicerinada, pero sin alcalinizar; el todo esterizado á $120^{\circ}$ en el autoclave, durante media hora. Examinado este cultivo con el microscopio se veía que era un cultivo puro del mismo parásito de la sangre palúdica." (Montoya y Flórez, 1904a, p.12)

10 "Este parásito afecta también a los sapos que parecen pues estar sujetos a una especie de caquexia palustre, caracterizada por una anemia profunda ... se trata ... de una enfermedad que ataca en tierras calientes más del 50 por ciento de estos batracios. ... también se encuentran en currucutúes, gavilanes, carraquíes, gallináceas, chuchas, carneros, curíes, conejos, caballos y mulas procedentes de regiones infestadas por el paludismo, lo mismo que en las garrapatas de esos animales." (Montoya y Flórez, 1904a, p.25)

${ }^{11}$ Las parasitosis epidémicas y endémicas son un fenómeno patológico emergente propio de la Revolución industrial. Las técnicas de penetración del subsuelo, de transformación de la naturaleza y las nuevas industrias allanadas por la invención de la máquina de vapor movilizaron y concentraron de forma inédita muchedumbres de trabajadores y sus familias hacia obras monumentales como canales interoceánicos, ferrocarriles, industrias mineras, etc. Colombia no escapó a esta nueva patocenosis mundial. La nueva situación demográfica, aunada a la ausencia de prácticas de civilización como el uso de calzado, el aseo corporal, la eliminación técnica de los excrementos, la higiene en el consumo de alimentos, coadyuvó a la emergencia de esas patologías colectivas. Las más renombradas, si no las más expandidas, fueron el paludismo y la anquilostomiasis, quizá por ser las que más impedían el libre curso del trabajo. Además estas dos enfermedades también estuvieron entre las más estudiadas y combatidas a finales del siglo XIX y comienzos del siglo XX (Grmek., Sournia, 1999; Fantini, 1999). En ese momento, Antioquia era un departamento cafetero, Montoya y su alumno Betancourt consideraban palustre la región cafetera porque allí abundaban "enfermos de anquilostomiasis": "Es común entre los peones que trabajan en cafetales observar la anemia que entre ellos produce el paludismo no febril y que los vuelve tuntunientos como aquí se les llama." (Betancourt, 1904, p.35)

12 Hijo de una distinguida familia antioqueña, en 1896 comenzó estudios de medicina en Medellín, se graduó en 1900 en la Facultad de Medicina de la Universidad de Antioquia con la tesis "Del suero artificial". En 1901, viajó como practicante al municipio de Titiribí (Antioquia). En 1905, aceptó la dirección médica de la empresa minera de El Zancudo en esa misma localidad, allí trabajó hasta 1911. En ese año fue elegido representante a la Cámara. En 1912, fue diputado a la Asamblea departamental de Antioquia y senador de la república. Fue rector de la Universidad de Antioquia entre 1913 y 1921 (Robledo, 1934).

13 Montoya y Flórez aceptaba las propiedades terapéuticas de la quinina, pero no sus propiedades profilácticas; por eso no podía admitir la ausencia de parásitos en la sangre de palúdicos tratados con dicho medicamento. En ese entonces, era conocido el efecto del uso continuado de la quinina y aun así el médico Montoya aprovechó esta observación compartida por muchos para argumentar que no existía el hematozoario descrito por Laveran.

14 Clorhidro-sulfato de quinina sublimado, biyoduro de mercurio, ácido fénico, timol, yodo, arsénico ácido salicílico, azul de metileno y fuscina (Montoya y Flórez, 1904a, p.28).

15 Definición del parásito de Littré: "La edad o la condición de un ser organizado que vive sobre otro ser organizado con la ayuda o en dependencia de su sustancia."

16 Las teorías parasitarias anteriores a Louis Pasteur se hayan expuestas en François Dagognet (1967, p.196227).

17 Sobre la idoneidad de la noción de programa de investigación de Imre Lakatos, para referirse a la medicina tropical de Manson en vez de la noción kuhniana de paradigma, véase la discusión planteada por Sandra Caponi (2003, p.133-147).

18 "un hecho curioso que se observa en el Hospital de esta ciudad [Medellín] consiste en que las sirvientas que trabajan en el lavadero del establecimiento sufren de paludismo, y no lo sufren las que no van al lavadero, lo que han tenido ocasión de comprobar cambiándoles de oficio a las mencionadas sirvientas. De este hecho ha 
deducido el Dr. Montoya que los mosquitos no tienen ninguna participación en la trasmisión de las fiebres, pues si así fuera, se verían atacadas tanto las que trabajan en el lavadero como las que lo hacen en los demás puntos del edificio, porque los mosquitos se encuentran allí en todas partes." (Acta, 1904b)

19 “Crudeli habla muy bien de la decocción del limón como profiláctico (que se obtiene hirviendo un limón tajado en una pinta y media de agua, y luego colando, diluyendo y endulzando): su uso no puede causar ningún daño. Y es una bebida agradable, ligeramente tónica y aperitiva, muy apropiada para beber en climas calientes. La decocción obtenida con un limón se puede tomar diariamente en varias dosis." La pinta es una medida inglesa que equivale en los Estados Unidos a 0,47 litros y en el Reino Unido a 0,57 litros. (Traducción y nota de Eduardo Cárdenas.)

20 "en los climas palustres hay individuos de los que llaman aclimatados que, aunque no presentan fiebres palustres, siempre tienen el germen del paludismo en la sangre ... . Esto parece probar que el microbio del paludismo puede vivir como comensal inofensivo en ciertas personas, hasta el momento en que un exceso, el hambre, un enfriamiento brusco, una fatiga física ó cualquiera otra causa que produzca un desequilibrio considerable hace estallar los excesos febriles". (Acta, 1904a, p.56)

${ }^{21}$ La noción de obstáculo epistemológico ha sido acuñada por el epistemólogo francés Gastón Bachelard, pero su uso en el estudio de la historia de las ciencias biomédicas ha sido impulsado por su discípulo François Dagognet (1967).

22 “Laveran creyó encontrar el parásito y fijó las formas bajo las cuales se presentaba en las preparaciones de sangre examinadas por él. Para Legrain el hematozoario de Laveran no es el que produce esta clase de fiebres, sino que según su concepto, el hematozoario en sus múltiples formas no es el germen febrígeno. El Dr. Montoya y Flórez cree lo mismo que Legrain respecto al hematozoario de Laveran. Los restos leucocitarios basófilos tomados por varios observadores como parásitos de Laveran, los ha encontrado el Dr. Montoya y Flórez, en las anemias profundas". (Betancourt, 1904, p.9).

${ }^{23}$ Betancourt y Montoya citan reiteradamente la obra Introduction à l'étude des fièvres des pays chauds (région prétropicale): la fièvre intermittente à quinine, les pyrexies et cachexies des pays chauds, de Émile Legrain (1899), pasteriano convencido.

${ }^{24}$ La historia natural, en Colombia, en el siglo XIX, se ocupó sobre todo de la catalogación de especies 'útiles', como las variedades de quina, el añil, las maderas, las plantas medicinales; pero también del conocimiento de la inmensa diversidad de especies animales, muchas de ellas promisorias económicamente. Insectos y microorganismos no eran de prioritario interés para los naturalistas, casi todos médicos. Los primeros estudios de historia natural de los insectos, publicados en Medellín, fueron en 1909 por un médico-naturalista, Andrés Posada Arango, quien conocía muy bien el territorio de los valles interandinos y pretendió hacer su 'geografía médica', empresa no realizada y muchas veces aplazada debido a su participación en las constantes guerras civiles del siglo XIX. En 1909, en su historia natural de los insectos de Colombia, decía de los zancudos: "Los Anopheles desempeñan un papel importante en la salubridad de las regiones palustres, pues está demostrado hoy que son agentes activos, si no únicos, de la transmisión de las fiebres palúdicas, inoculando los hematozoarios por medio de sus picaduras. Hay autores, como el italiano Dr. Grossi, que dicen que sin Anopheles no hay paludismo. No somos nosotros tan exclusivistas: creemos que pueden adquirirse tales fiebres, por sólo respirar el aire de la noche en esas localidades; por tomar malas aguas o por bañarse en ellas, y aún por tomar fruta y leche cruda." (Posada Arango, 1909, p.397-398). Sobre el impacto de las tesis mansonianas en la propuesta de nuevas investigaciones en historia natural en Colombia no se ha realizado aún ninguna investigación histórica.

25 No existían comparaciones provenientes de la medicina tropical como dos décadas antes, cuando se habló del papel que tienen los mosquitos en la propagación de la filariosis (Manson, Hanoi, 1878) y de la fiebre amarilla (Carlos Finlay, Cuba, 1881) y estas enfermedades fueron el modelo heurístico para elucidar los mecanismos de transmisión de la malaria (Ross, Grassi, 1898) y la fiebre amarilla (Reed, 1900). Véase: Delaporte (1989).

${ }^{26}$ El historiador Bernardino Fantini (1999) sintetiza así esta posición de los pasterianos: “Uno de los obstáculos mayores en el reconocimiento de los protozoarios como causa patógena viene del hecho de que estos microorganismos cumplen ciclos de vida complejos, necesitan con frecuencia huéspedes intermediarios o vectores, lo que hace muy difícil su cultivo en laboratorio."

27 La expresión es de François Dagognet (1967).

28 Sobre la mezcla y la vaguedad de las doctrinas referente a lo tropical en medicina vale la pena citar a otra historiadora: "Haciendo un recuento de nuestra documentación, durante la primera parte del siglo XX, reconocemos que los proyectos que se llevaron a cabo sobre 'Medicina Tropical' constituyeron aquí un conjunto de explicaciones, discusiones, confusiones. Se leen las obras más relevantes sobre 'Medicina tropi$\mathrm{cal}^{\prime}$, se citan grandes teóricos del tema, pero en muchos casos el resultado son artículos en los cuales la información se cruza; se habla de lo tropical para referirse a lo deletéreo, se ponen en el mismo nivel de discursividad los miasmas que contienen aguas estancadas y los mosquitos trasmisores de la enfermedad". (López, 1998, p.95-96) 
${ }^{29}$ El médico colombiano Roberto Franco Franco, nació en 1874 en Chimbe (Cundinamarca), se graduó en la Universidad Nacional de Colombia en 1897. Viajó a París donde realizó estudios en medicina (y de parasitología con el médico Raphael Blanchard). También hizo el curso de microbiología del Instituto Pasteur de París con Roux, Metchnikoff, Laveran y Sergent. Se graduó de médico en París el 3 de diciembre 1903. En 1903, también aparece como alumno del recién creado Instituto de Medicina de Colonial de París. Posteriormente, se matriculó en la Escuela de Medicina Tropical de Londres, donde pudo haber tenido contacto con Manson, aunque allí sólo estuvo cuatro meses y no obtuvo ningún título. (Quevedo et al., 2004). En 1904, el doctor Franco ya estaba trabajando en Bogotá y en diciembre de ese año logró la aprobación de la primera cátedra de Medicina tropical en Colombia, en la Universidad Nacional.

30 "Se ven los elementos perfectamente fijados por el alcohol metílico, que por sí solo es uno de los reactivos mejores para fijar así: los leucocitos de todas las clases, de color violeta, los glóbulos rojos de color rosado y los hematozoarios azules." (Zea Uribe, 1904, p.134).

31 Y Zea Uribe (1904, p.35) concluye: "1ำ la entidad mórbida conocida entre nosotros con el nombre de paludismo, es esencialmente idéntica á la conocida con ese nombre en las regiones templadas y tropicales del Antiguo Continente; $2^{\circ}$ en la sangre de nuestros palúdicos que no han sido sometidos al tratamiento por la quinina, examinada en pleno estado febril, existe siempre el hematozoario de Laveran."

32 "En los estudios bacteriológicos sobre paludismo se opera actualmente una revolución que encabezan hombres eminentes en la ciencia, y es muy probable que toque al Dr. Montoya una parte muy importante en las rectificaciones comenzadas. Gloria en verdad muy grande para él y para Colombia." (Delgado, Zuleta, 1905, p.376). Otro artículo publicado en mayo de 1904 en Bogotá, el médico José María Lombana Barreneche (1904, p.300) reafirma "la novedad de las opiniones del Dr. Montoya y Flórez y su indiscutible competencia en estas materias".

33 Véase, por ejemplo, De Parrille (1899), Gómez (1903) y Carrasquilla (1903). En particular, en la primera época de los Anales de la Academia de Medicina de Medellín (1888-1916) se menciona muy poco el papel de los insectos en la transmisión de enfermedades.

34 En la región antioqueña no encontramos artículos médicos sobre el tema antes de 1913, se debe aclarar que entre 1905 y 1911 la Facultad de Medicina de Medellín estuvo cerrada. Las razones de este cierre son muy diferentes a las de aquel que sufriera la Universidad entera en 1900, cuando fue convertida en cuartel militar. En 1905, algunos republicanos liberales, encabezados por el rector Tulio Ospina, consideraron que había desterrar toda enseñanza literaria y humanista e impulsaron una reforma que abolía la Facultad de Filosofía y Letras, la Escuela de Derecho y la Escuela de Medicina. Esta última funcionó parcialmente, sin presupuesto, sin salarios para los profesores, entre 1905 y 1908 y fue cerrada completamente entre 1908 y 1911 por falta de apoyo e interés de parte de la rectoría (Uribe de Hincapié, 1998, p.217).

35 Son ecos de las enseñanzas de Claude Bernard, en Principes de médecine expérimentale: "Sin duda había que lanzarse primero en la vía experimental .... Pero esto no basta: no es suficiente querer hacer experiencias para hacerlas; hay que saber bien lo que se quiere hacer y hay que evitar el error en medio de esa complejidad de estudios; hay que fijar el método y esa es mi parte." (citado en Dagognet, 1998)

36 “Tres factores principales intervienen en la génesis del paludismo: un organismo sensible al virus, el hombre; un insecto que sirve de medio de transmisión del virus es el anopheles y un factor terreno que sirve de cultivo al mosquito: es el agua de los pantanos etc. etc." (Rueda, 1907, p.29) Las medidas profilácticas deben evitar la conjugación de esos tres factores.

37 Uno fue tomado de la Revue Universelle, aparece firmado por las iniciales Dr. FH.P. y expone "medios para destruir los mosquitos" recomendados por el médico M.J. Chatin. El segundo texto es un fragmento de un artículo publicado por el periódico El Espectador de Medellín bajo las iniciales P.R.V. En éste se expone la posible amenaza de la fiebre amarilla en Medellín debido a las condiciones favorables para la proliferación de los mosquitos y el gran peligro que constituye la abundancia de mosquitos en la ciudad de Puertoberrío.

${ }^{38}$ Los casos de malaria tratados en 1911 fueron 2,317-22 enfermos promedio por mil obreros, mientras en 1912 fueron 1,317-46 (Henao, 1916, p.311).

39 “Como el promedio de obreros del Ferrocarril en 1912 fue de 630 dejaron de enfermar 629,8 obreros debido a las mejores condiciones existentes, lo cual representa un ahorro nominal de $\$ 2.223,19$ oro, considerando el costo de cada enfermo en $\$ 3,53$, promedio al año." (Henao, 1916, p.310)

${ }^{40}$ Henao promueve los seguros de invalidez y las pensiones por accidente de trabajo, indicios de la modernidad de su pensamiento. 


\section{REFERENCIAS BIBLIOGRÁFICAS}

Acta ...

$1904 a$

Acta...

1904b

Andrade, José Luis 1891

Betancourt V., Francisco 1904

Botero Guerra,

Marco A.

1889

Bourdieu, Pierre 2003

Caponi, Sandra jan.-abr 2003

Carrasquilla, Juan de Dios 1903

Dagognet, François 1998

Dagognet, François 1967

De Parrille, Henri 1899

Delaporte, François 2004

Delaporte, François 1989

Delgado, Jorge E.;

Zuleta, Eduardo 1905

Estrada Orrego,

Victoria. 2004

Fantini, Bernardino 1999

Gómez, Proto 1903

Grmek, Mirco Drazen;

Sournia, Jean-Charles 1999

Henao, Emiliano 1916
Acta de la sesión del día 12 septiembre de 1904. Anales de la Academia de Medicina de Medellín, Medellín, v.13, n.3-4, p.55-62.

Acta de la sesión del dia $1^{\circ}$ de agosto de 1904 (ordinaria). Anales de la Academia de Medicina de Medellín, Medellín v.13, n.3-4, p.50.

Estudio sobre la diarrea endémica de los países cálidos. Tesis de Medicina - Universidad Nacional, Bogotá.

Contribución al estudio del paludismo en Antioquia. Medellín: Tipografía popular. Tesis de Medicina - Facultad de Medicina y Cirugía de Medellín, Medellín.

Variedad de fenómenos engendrados por los miasmas palúdicos. Anales de la Academia de Medicina de Medellín, Medellín, v.2, n.1, p.36-40.

El oficio de científico: ciencia de la ciencia y reflexividad. Madrid: Anagrama.

Coordenadas epistemológicas de la medicina tropical

História, Ciências, Saúde-Manguinhos, Rio de Janeiro, v.10, n.1, p.113-149.

El paludismo y los anofelos.

Revista Médica de Bogotá, Bogotá, v.24, n.280, p.35-44.

Une introduction à Claude Bernard. In: Dagognet, François. Savoir et pouvoir en médecine. Paris: Synthélabo.

Méthodes et doctrine dans l'oeuvre de Pasteur.

Paris, PUF.

Revista de Ciencias (De la Correspondani). Anales de la Academia de Medicina de Medellín, Medellín, v.10, n.3-4, p.90-97.

Parasitologie. In: Lecourt, Dominique (dir.).

Dictionnaire de la pensée médicale. Paris: PUF.

Historia de la fiebre amarilla: nacimiento de la medicina tropical. México: CEMCA-UNAM.

Informe sobre los trabajos del doctor Montoya y Flórez relativos al microbio del Paludismo. Revista Médica de Bogotá, Bogotá, v.25, n.303, p.374-376.

Comienzos de una epidemiología de terreno en Colombia. In: Márquez Valderrama, Jorge (dir.). Higienizar, medicar, gobernar: historia, medicina y sociedad en Colombia. Medellín: Universidad Nacional de Colombia. p.127-158.

La microbiologie médicale. In: Grmek, Mirco Drazen (Éd). Histoire de la pensée médicale en Occident. Paris: Seuil. v.3, p.115-146.

Los mosquitos de la fiebre amarilla.

Revista Médica de Bogotá, Bogotá, v.24, n.280, p.653-659.

Les maladies dominantes. In: Grmek, Mirco Drazen (Éd.).

Histoire de la pensée médicale en Occident. Paris: Seuil. v.3, p.271-293.

La higiene en el ferrocarril de Antioquia. In: Congreso Médico de Colombia, 2, 1913, Medellín. Segundo Congreso Médico de Colombia. Bogotá: Escuela Tipográfica Salesiana. tomo 2, p.309-314. 


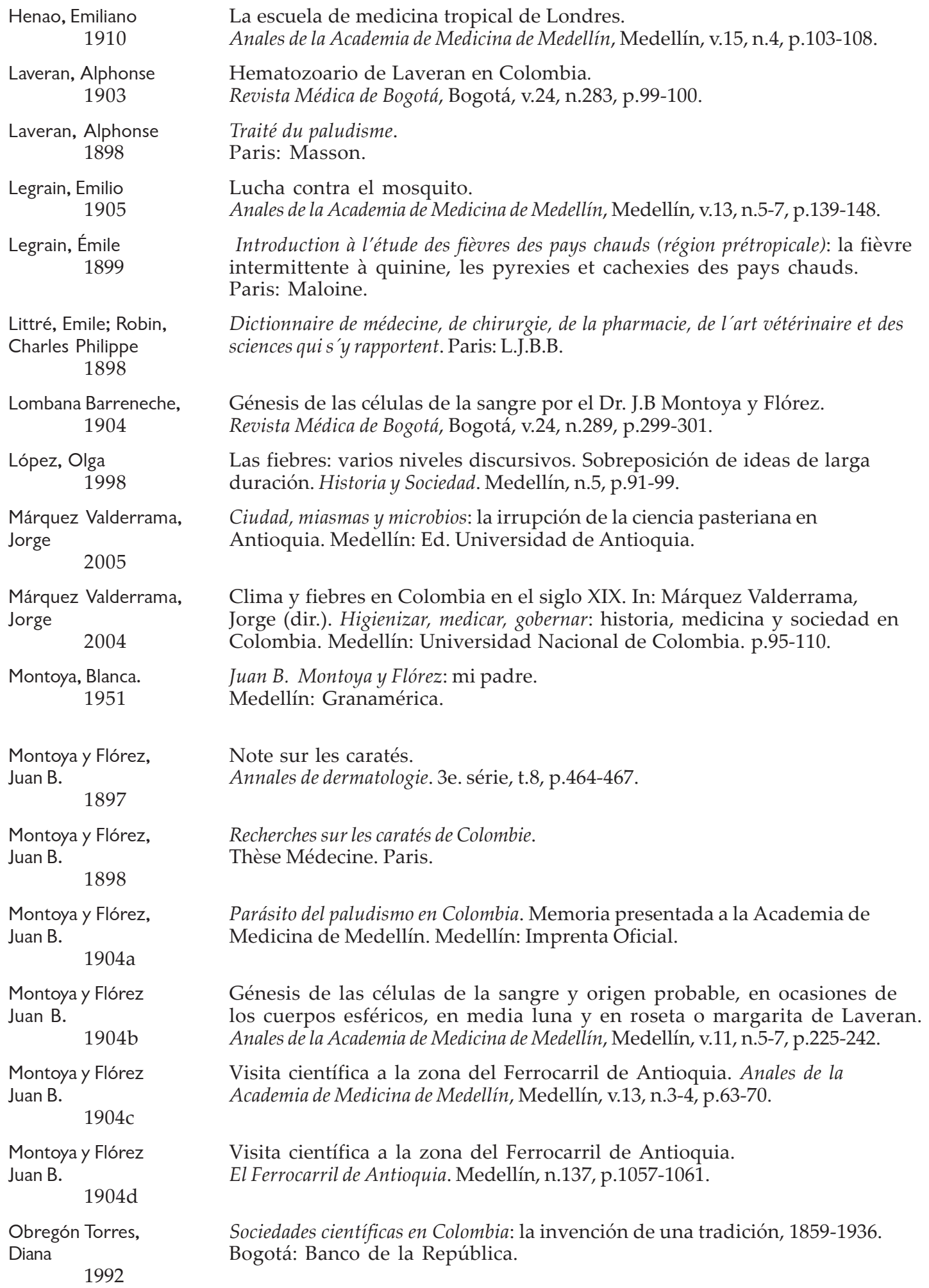

Anales de la Academia de Medicina de Medellín, Medellín, v.15, n.4, p.103-108.

Hematozoario de Laveran en Colombia.

Revista Médica de Bogotá, Bogotá, v.24, n.283, p.99-100.

Traité du paludisme.

Paris: Masson.

Lucha contra el mosquito.

Anales de la Academia de Medicina de Medellín, Medellín, v.13, n.5-7, p.139-148.

Introduction à l'étude des fièvres des pays chauds (région prétropicale): la fièvre intermittente à quinine, les pyrexies et cachexies des pays chauds. Paris: Maloine.

Dictionnaire de médecine, de chirurgie, de la pharmacie, de l'art vétérinaire et des sciences qui s'y rapportent. Paris: L.J.B.B.

Génesis de las células de la sangre por el Dr. J.B Montoya y Flórez. Revista Médica de Bogotá, Bogotá, v.24, n.289, p.299-301.

Las fiebres: varios niveles discursivos. Sobreposición de ideas de larga duración. Historia y Sociedad. Medellín, n.5, p.91-99.

Ciudad, miasmas y microbios: la irrupción de la ciencia pasteriana en Antioquia. Medellín: Ed. Universidad de Antioquia.

Clima y fiebres en Colombia en el siglo XIX. In: Márquez Valderrama, Jorge (dir.). Higienizar, medicar, gobernar: historia, medicina y sociedad en Colombia. Medellín: Universidad Nacional de Colombia. p.95-110.

Juan B. Montoya y Flórez: mi padre.

Medellín: Granamérica.

Note sur les caratés.

Annales de dermatologie. 3e. série, t.8, p.464-467.

Recherches sur les caratés de Colombie.

Thèse Médecine. Paris.

Parásito del paludismo en Colombia. Memoria presentada a la Academia de Medicina de Medellín. Medellín: Imprenta Oficial.

Génesis de las células de la sangre y origen probable, en ocasiones de los cuerpos esféricos, en media luna y en roseta o margarita de Laveran. Anales de la Academia de Medicina de Medellín, Medellín, v.11, n.5-7, p.225-242.

Visita científica a la zona del Ferrocarril de Antioquia. Anales de la Academia de Medicina de Medellín, Medellín, v.13, n.3-4, p.63-70.

Visita científica a la zona del Ferrocarril de Antioquia.

El Ferrocarril de Antioquia. Medellín, n.137, p.1057-1061.

Sociedades científicas en Colombia: la invención de una tradición, 1859-1936. Bogotá: Banco de la República. 
Pérez, David

1901

Posada Arango,

Andrés

1887

Quevedo, Emilio et. al. 2004

Restrepo, Libia 2004

Robledo, Emilio. Doctor Miguel María Calle. 1934

Rueda, Jorge D. 1907

Uribe Ángel, Manuel. 1888

Uribe de Hincapié, María T. 1998

Zea Uribe, Luis. 1904
Contribución al estudio de la higiene de las regiones cálidas de Colombia. Medellín: Imprenta Departamental. Tesis de Medicina - Universidad de Antioquia, Medellín.

Estudios científicos. Medellín: Imprenta Oficial. 1909Posada Arango, Andrés. Consideraciones sobre los efluvios telúricos: higiene de los viajeros en los climas calientes. Anales de la Academia de Medicina de Medellín, Medellín, v.1, n.2, p.61-66.

Café y gusanos, mosquitos y petróleo: el tránsito desde la higiene hacia la medicina tropical y la salud pública en Colombia, 1873-1953.

Bogotá: Universidad Nacional de Colombia.

La práctica médica en el Ferrocarril de Antioquia, 1875-1930.

Medellín: La Carreta Ed.

Boletín Clínico, s.1., n.1, v.8, p.341-346.

Contribución al estudio del aludismo en Colombia.

Tesis de Medicina - Universidad Nacional, Bogotá.

La medicina en la zona tórrida.

Anales de la Academia de Medicina de Medellín. Medellín, v.1, n.4, p.101-108.

Las reformas de Tulio Ospina. In: Uribe de Hincapié, María T. (Ed.).

Universidad de Antioquia: historia y presencia. Medellín: Universidad de Antioquia, p.217-220.

A propósito del hematozoario de Laveran.

Revista Médica de Bogotá, Bogotá, v.25, n.296, p.129-135.

Recebido para publicación en septiembre de 2004.

Aprobado para publicación en julio de 2006. 